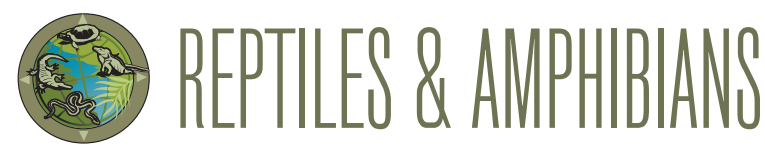

\title{
Observations of Predation by an Indian Bullfrog (Hoplobatrachus tigerinus) and a Banded Krait (Bungarus fasciatus)
}

\author{
Prasanna Kalita ${ }^{1}$, Jyoti Kumar Das ${ }^{1}$, Mrigen Mishra ${ }^{2}$, and Jayaditya Purkayastha ${ }^{3}$ \\ ${ }^{1}$ Bonyabondhu, Kamrup 781132, Assam, India \\ ${ }^{2}$ Kamrup 781132, Assam, India \\ ${ }^{3}$ Help Earth, Raghunath Choudhury Path, Lachitnagar, Guwahati 781007, Assam, India (mail.jayaditya@gmail.com)
}

Tndian Bullfrogs (Hoplobatrachus tigerinus) are known to Le voracious feeders that consume a variety of invertebrate and vertebrate prey (Khan 1973; Padhye et al. 2008; Rahman et al. 2012; Dutta and Khaledin 2017; Mishra 2017; Tripathi 2018; Mohanty and Measey 2019; Vazifdar et al. 2021). Herein we report the predation of a Western Painted Bronzeback (Dendrelaphis proarchos) by an Indian Bullfrog at Nahira, Kamrup District, Assam, India $\left(26^{\circ} 06^{\prime} 41.23^{\prime \prime N}\right.$, $91^{\circ} 28^{\prime} 20.25^{\prime \prime E}$ ) at ca. $1420 \mathrm{~h}$ on 15 September 2017 (Fig. 1). Both prey and predator were adults and complete ingestion of the snake took about 45 minutes including periodic breaks.

At ca. 2250 h on 10 August 2021, we observed an adult Banded Krait (Bungarus fasciatus) preying on a Lesser Black Krait (Bungarus lividus) at Dakhala, Kamrup District, Assam, India (2606'36.36"N, 91²9'38.41"E) (Fig. 2). Complete ingestion took about 30 minutes. Banded Kraits are known to be ophiophagus and records of prey include at least 13

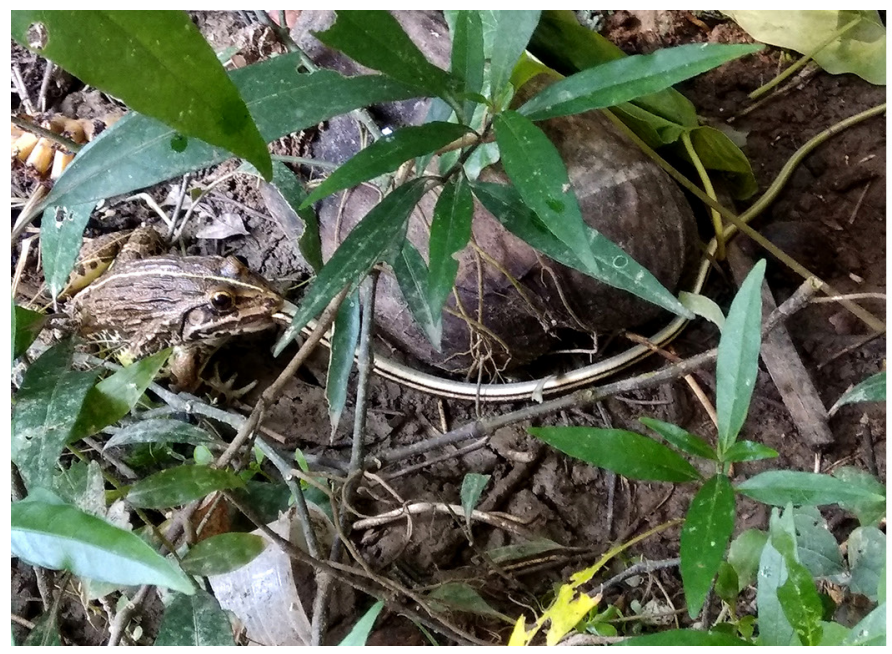

Fig. 1. An Indian Bullfrog (Hoplobatrachus tigerinus) preying on a Western Painted Bronzeback (Dendrelaphis proarchos). Photograph by Mrigen Mishra. species of snakes (Daniels 2002; Bharos 2013; Knierim et al. 2017; Luu and Ha 2018; Lalbiakzuala et al. 2019).

To the best of our knowledge both of these observations document novel prey of their respective predators.

\section{Literature Cited}

Bharos A.M.K. 2013. Banded Krait Bungarus fasciatus feeding on Common Krait Bungarus caeruleus. Journal of the Bombay Natural History Society 110: 155156.

Daniels, J.C. 2002. The Book of Indian Reptiles and Amphibians. Bombay Natural History Society and Oxford University Press, Oxford, UK.

Dutta, A.K. and S. Khaledin. 2017. Observations on an Indian Bull Frog swallowing an Asian Common Toad, and a Checkered Keelback on a Skipper Frog. Frog Leg \#132 in: Zoo's Print 32(6): 28-29.

Khan, M.S. 1973. Food of tiger frog Rana tigerina Daudin. Biologia 19: 93-107.

Knierim, T., C.H. Barnes, and C. Hodges. 2017. Bungarus fasciatus (Banded Krait). Diet/scavenging. Herpetological Review 48: 204-205.

Lalbiakzuala, Lalrinsanga, H.T. Lalremsanga, Romalsawma, Vanlalhrima and H. Laltlanchhuaha. 2019. Bungarus fasciatus (Banded Krait). Diet. Herpetological Review 50(4): 797.

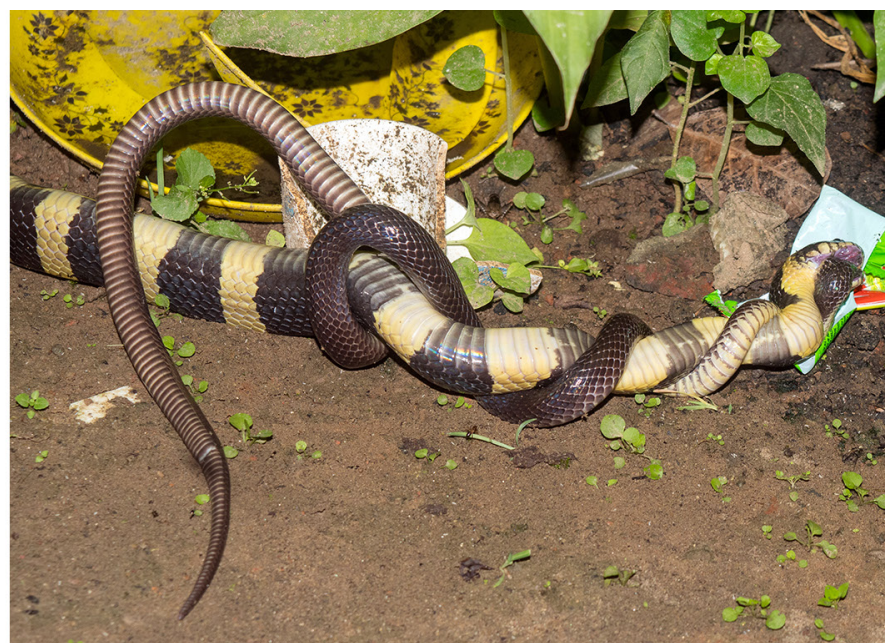

Fig. 2. A Banded Krait (Bungarus fasciatus) preying on a Lesser Black Krait (Bungarus lividus). Photograph by Prasanna Kalita. 
Padhye, A., K. Manamendra-Arachchi, A. de Silva, S. Dutta, T. Kumar Shrestha, S. Bordoloi, T. Papenfuss, S. Anderson, S. Kuzmin, M.S. Khan, and R. Nussbaum. 2008. Hoplobatrachus tigerinus. The IUCN Red List of Threatened Species 2008: e.T58301A11760496. https://dx.doi.org/10.2305/IUCN. UK.2008.RLTS.T58301A11760496.en.

Luu, V.Q. and N.V. Ha. 2018. Bungarus fasciatus (Banded Krait). Diet. Herpetological Review 49: 543.

Mishra, S.B. 2017. Hoplobatrachus tigerinus (Indian Bullfrog). Diet. Herpetological Review 48: 162.

Mohanty, N.P. and G.J. Measey. 2019. What's for dinner? Diet and potential tro- phic impact of an invasive anuran Hoplobatrachus tigerinus on the Andaman Archipelago. PeerJ 6: e5698. https://doi.org/10.7717/peerj. 5698.

Rahman, S.C., W.I. Opu, and K.R. Das. 2012. Lycodon aulicus (Common Wolf Snake). Predation. Herpetological Review 43: 346.

Tripathi, R. 2018. Predation record on Duttaphrynus species by Hoplobatrachus tigerinus (Daudin 1802). Frog Leg \#134 in: Zoo's Print 33(4): 10-11.

Vazifdar, N., M.A. Khalid, and K. Lahon. 2021. Attempted predation of an Andaman Bronzeback (Dendrelaphis andamanensis) by an Indian Bullfrog (Hoplobatrachus tigerinus) on Havelock Island, Andaman and Nicobar Islands, India. Reptiles and Amphibians 28: 535-536. https://doi.org/10.17161/randa.v28i3.15772. 